\title{
SYPHILITIC PARESIS.
}

By SAMUEL J. WIGHTMAN, M.D.,

LATE RESIDENT PHYSICIAN OF CITY HOME AND INSANE ASYLUM, PITTSBURG, PA.

YPHILITIC paresis is seldom recognized by the proNession as a separate disease, but is classed among the rheumatoid affections; and although it simulates rheumatism in various ways, it is a distinct disease of itself.

CASE I was twenty-seven years of age, white; born in New York State, and of Irish parentage. He came under my care on the I 8 th of January, I879, suffering with stiffness in all his joints. He was a silver-plater by trade, and like most young men of his class, was intemperate, and had acquired syphilis a few years before.

With a history somewhat like the above, he had entered Western Pennsylvania Hospital (twelfth ward division) about three months previous to the above date, and was placed on the anti-syphilitic treatment, consisting of potass., iodid., and hydrarg. chlorid. cor. in solution. But he grew worse rather than better, and was finally discharged as incurable. For the rheumatic trouble which he was supposed to be suffering from later in the disease, he had been treated with acid salicylicum. When first seen by me his tongue was pale; pulse 88 , full and strong; bowels regular; appetite bad; temperature normal $\left(98 x / 2^{\circ}\right)$, urine high-colored and scant; had pains in his arms and legs while standing or moving about, but sitting upon the chair or lying upon the bed he was somewhat at ease. When he attempted to walk he had power to move his feet only two inches apart, either forward, backward, or sidewise. His legs and arms were stiff and painful, but the arms not to so great an extent as 
the legs, and he had a tenderness on pressure in the inferior dorsal region about the neighborhood of the twelfth dorsal and first lumbar vertebræ.

Following the treatment laid down for such cases (especially when acidum salicylicum had failed), I gave him the same treatment he had been given formerly, namely: potass. iodid. and hydrarg. chlorid. cor., adding in connection a small (two by four) emplastrum cantharidis on the tenderness upon the back, which relieved so long as the surface remained broken. I persisted in this treatment for about a month, with little or no good results. I then re-studied the case.

$\mathrm{He}$ had been cured of his syphilitic trouble with mercury. The syphilis had never troubled him after treatment. He took cold about four months previous to my seeing him, and was supposed to be suffering from the fumes arising from melting silver while at work. I discovered by closer observation that the spinal cord was affected, and that the syphilis played a prominent part in his trouble. With this new discovery I discarded the treatment I had expected so much from, and placed him on oleum morrhuæ. As his blood was in an anæmic condition, I gave him, in addition to the oil, tmeti. ferri perchloridi.

The effect was magical. Three months after this change of treatment I had him moving about the dining-room assisting the man who had charge of the wards. His limbs, however, did not resume their suppleness for fully another quarter, at the end of which time I appointed him ward-master, and he remained with me for a year afterward, when I was able to pronounce it a complete cure.

It would be asked why oleum morrhuæ had so great an effect upon this case when potass. iodid. failed. I attribute it to the iodine which is found pure in the oil. The disease had become a nervous affection. Mercury and syphilis had made their attack upon the spinal cord (dorsal and lumbar region), retarding the circulation of the nervous fluid along the great sciatic nerve, more especially the supply to the peripheral nerves. The iodine in the oil took up the deleterious matter and removed it; at the same time the fatty constituents improved his constitution.

CASE 2 was twenty-four years of age, white, female; born in 
Missouri, and of Irish parentage. She first came under my care on the I 9 th of March, I88o, suffering with active syphilis. She had a bubo on left side and a purulent discharge from vagina; a hard chancre upon labia majora; her system was exhausted; had a slight fever, and her appetite was not the best. Under treatment she soon recovered and left the hospital on the 19 th of April, I 880 .

She enjoyed good health after this for about a year and a quarter, when she came back in a worse condition, entering the hospital, ${ }^{1}$ the second time, on the rath of August, I88I. She was a courtesan, and partook of the wild life incident upon girls of that character. Having caught cold a few days previous, from exposure, the old complaint came back in a worse form. She had severe pain in her arms, lower limbs, and shoulders, pain in right side; tongue furred and coated ; pulse 86 , full and weak ; appetite moderate, with a feeling of nausea; bowels regular; and temperature $100^{\circ} \mathrm{F}$. She had large copper-colored spots over the whole of the body, which was the only sign of syphilis present. She suffered from insomnia, and had stiffness of the arm, forearm, and shoulder.

Having her under treatment before and knowing her former history, I gave her large doses of potass. iodid. The second night after she began this treatment she gained some rest, and on the third the pain had subsided, and the sixth found the stiffness entirely removed, and she left the Home about the I 2 th of September entirely well.

Iodine in its favorite combination was administered in this case with good results. The disease had just begun to show the secondary manifestations, is one reason I attribute why the drug acted so promptly.

CASE 3 was twenty-six years of age, white, male; born in Ireland, and of Irish parentage; came under my care on the 6 th of October, r88I. He had been suffering for six days with pains and stiffness about the lower limbs.

He had syphilis two years before, and was cured of the trouble with the usual drugs. Had a severe pain in the left hip ; irregular action of the heart; tongue pale and coated white; bowels costive : appetite poor : pulse 8o and irregular, and temperature

${ }^{1}$ Pittsburg City Home Hospital. 
$991^{\circ} \mathrm{F}$. Recognizing the syphilitic diathesis I gave him potass. iodid. and hydrarg. bichlorid. in solution.

October the i th found him, if any, but slightly improved. $\mathrm{He}$ had a bad night, with the pain in the hip, which was not so severe during the day as it was during the night; his hearing was also affected; tongue furred, but not so coated as before; appetite bad; bowels regular; temperature $994^{\circ} \mathrm{F}$.; pulse 60 , full and strong; urine high-colored and free; his skin was sallow but moist; he had a lightness in the head, a wild look about the eyes, and his mind wandered during the night. Although he did not show that marked improvement he should have done, still I continued the above treatment.

October 16 th he was very little, if any, improved. The pain about the hip still troubled him, although with not that severity it had formerly; his eyes were slightly congested; tongue furred and coated; bowels regular; appetite better; urine high-colored and free; temperature $99 \mathrm{I} / 4^{\circ} \mathrm{F}$; ; and pulse 59 , full and strong. Although the pain was not so severe, yet the parts were very tender, and he was unable to move his limb or walk about. Still I continued the treatment.

October $23 \mathrm{~d}$ he was slightly better, but not so marked as I had expected. The pain had increased in severity during the night and lasted until six o'clock this morning; ${ }^{1}$ his eyes were still congested; tongue coated and fringed with purple; pulse 65 , full and strong; appetite fair; hearing, if any change, duller; face flushed; his head still felt light, attended with a pain along the frontal sinuses; bowels regular; and temperature $99 \mathrm{I}^{\mathrm{I}}{ }^{\circ} \mathrm{F}$. He was still almost bedridden, and it was with great difficulty he moved from his bed to the water-closet, which was in an adjoining room, about one hundred feet from him. I now took him off the hydrarg. iodid. and placed him on simple tinct. iodine giving two-drop doses repeated often. In connection with this, I gave him a vegetable purgative to relieve a congestion of the brain with which he was threatened.

Nov. Ist the pain in the hip was not so severe, except at such times as he attempted to move about, when it attacked hin with severity. The appetite was good; urine free ; pulse, 56, full and strong; temperature, $99 \mathrm{I}^{\mathrm{O}} \mathrm{F}$.; tongue slightly coated ; and face flushed moderately. He had been lying in a reclining position for

${ }^{1}$ It had been cool all night. The steam in the heaters was not sufficient to keep the room above $45^{\circ} \mathrm{F}$., but about 5.30 A.M. the boilers were fired up and the temperature arose to $80^{\circ} \mathrm{F}$. 
the last few days with very little pain and no excitement, and presenting a sort of vacuity in his countenance. The iodine treatment was continued with an emplastrum cantharidis upon the spine about the inferior dorsal region.

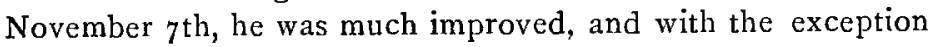
of a slight frontal cephalalgia (which annoyed him) he was free from pain. The tongue was still coated and furred; appetite was good; bowels regular; urine high-colored and scant ; pulse, 70, full and strong; heart's impulse strong; temperature $100^{\circ} \mathrm{F}$.; face flushed; and pupils dilated. The hip was sore, but not so painful except at times he attempted to exercise it, and was sore about the abdomen. Although the pain was felt only about the hip, yet all his joints were more or less stiff, and the brain was congested, causing that slow action of the heart which is noticed above. There was no evidence of swelling about any of the joints that could indicate inflammatory trouble, $I$ therefore continued my treatment of the "tincture of iodine."

$H$ is recovery from this time forward was rapid, and he was discharged on the $19^{\text {th }}$ of December, $188 \mathrm{I}$, being in the hospital two months and twelve days under treatment.

The symptoms of this case simulate morbus coxarius so much I do not feel like departing from it without saying a few words on that disease.

That it was not morbus coxarius, the termination of the case confirmed. The pain, which was intense, was not the pain of that disease. Although it was constant, yet handling did not increase it. The temperature was not increased. There were no signs of swelling about the hip much less about any of the other joints; and although the rotation of the thigh was severe, yet it did not produce that intense feeling which is experienced in inflammations of the synovial covering of the acetabulum; and further there was neither lengthening nor shortening; nor was there that contraction of the muscles which follow a protracted inflammation of that membrane. No tenderness on pressure except upon the spine, and it seemed to be an irritation rather than an inflammation of the great sciatic nerve at its exit from the 
pelvis; besides these points there was a stiffness of all the joints without an increase of heat or swelling. The syphilitic diathesis also aided me in my diagnosis.

CASE 4 was a male, white, thirty-four years of age ; born in Ireland and of Irish parentage ; came under my care on the 15 th of October, r 88 r.

He had acquired syphilis two years before, and was (as he thought) cured completely. About forty-nine days before entering the hospital, he took sick with pains in the back (inferior dorsal region) and limbs, and was unable to lift the left arm and leg. He had an idiotic look and rambling talk. His bowels were regular ; appetite good ; temperature $99 \mathrm{I}^{\circ} \mathrm{F}$; pulse $9 \circ$, full and strong; urine free; and tongue coated white. He had also a cataract in left eye. The pain in the back was so severe, and the joints so stiff, he was unable to move about or change his position. Recognizing the syphilitic nature of the disease, I prescribed potass, iodid,. and hydrargyri bichlorid. in solution.

October $23 \mathrm{~d}$ he was better; tongue red and furred; appetite good; bowels regular; urine free; temperature $99 \mathrm{r} / \mathrm{o}^{\circ} \mathrm{F}$.; and pulse 8o., full and strong. He had now been eight days under the iodine treatment, and the improvement was so marked, I continued it. He was able to move to and fro from his bed, lift his arm above his head, flex his legs full, and shut his hand without any difficulty. The pain in the back lingered, giving him some trouble at night, so that $\mathrm{I}$ increased the dose, giving him as high as sixty grains of potass. iodide, and half a grain of hydrargyri bichlorid., in twenty-four hours.

November ist found him so far improved as to be able to move about without suffering much from the pains in his arms and legs, that still annoyed him. The tongue was slightly coated; bowels were regular; appetite good ; urine free but scant ; pulse 86, full and strong; and temperature $99^{\circ} \mathrm{F}$. His skin was dry, and his countenance had a cast of anguish about it. I thought he must be suffering more than he would acknowledge. But he did not complain, and I continued giving him the potass. iodid. and hydrarg. treatment, though at the rate of forty grains of the potassium salt to one-fourth grain of the hydrargyrum in twentyfour hours.

November $3 \mathrm{~d}$ he left the institution against my wishes. He was so free from pain, however, that he expected to go to work as 
soon as he reached the city, having heard of a place from one of the inmates before leaving.

CASE 5 was a male, white, forty-three years of age; born in Germany, and of German parentage. He had acquired syphilis several years before, and was cured by the usual treatment versus iodine and mercury. Came under my care on the 3oth of December, I88r. Took sick about four months before with stiffness of the arms and legs attended with severe pain. He received no treatment all this time, and was allowed to suffer until the cerebral centres were attacked, when he was brought to the Home hospital. His temperature stood $102^{\circ} \mathrm{F}$, indicating an inflammatory trouble ; his pulse 94, but full and strong; tongue pale and fringed with red; appetite poor; bowels loose; and he passed his urine freely. His mind was weak, and when he attempted to move about he staggered; was incoherent in his speech, and upon the whole presented a melancholic aspect. He also complained of a frontal cephalalgia, and had a catarrhal cough. Following the regular line of treatment, I placed him on potass. iodid., etc.

January $\mathbf{I}, \mathbf{1} 882$, his condition was worse. The temperature had risen to $103^{\circ} \mathrm{F}$; the pulse 96 , full but feeble; bowels costive ; tongue coated and moist; appetite still remained poor; urine passed freely; his speech was incoherent; he staggered in his gait, and he had to have a person with him constantly attending to him.

Recognizing the debilitated condition into which he had sunk, I placed him on a ferruginous and stimulant treatment, discarding the potass. iodid. I did not, however, obtain any good results from the change of treatment, but he sank gradually into a lethargic state, and died on the 9 th of January, $\mathbf{I} 882$.

The autopsy was held twenty-four hours after death. The dura mater, external or fibrinous layer, was extensivley congested. Adhesion of the fibrinous and serous layers near the frontal sinuses, left side. Granulations of inflammation on the internal surface of internal or serous layer, and on the arachnoid covering in both hemispheres about the region of the supralongitudinal sinus; subarachnoid space distended with a serous fluid, and the plexus of pia mater somewhat congested. The other parts of the brain appeared to be healthy.

The medulla oblongata was slightly congested, which I supposed was partly from the action of gravitation.

The cervical cord was the only part of the spine examined, and it was very much softened. Dissolution had set in, and I deemed it of no use to obtain sections of it. 
Syphilis has long been known as a most destructive disease, leaving its impress upon the system long after the virus has been apparently destroyed. It is to the present age what leprosy was to the Jews, being a curse to the party who has acquired it. There are few who can flatter themselves that they are ever free from it, the inertia of the germ being no proof of its destruction. For although it may be latent in the person who acquired it, yet it is transmissible to the offspring. In the study of the disease this hereditary diathesis must not be overlooked. We must not limit ourselves to individual acquirement. It has, however, generally been looked upon as a dissecting disease ulcerating the body and destroying life by its exhaustion of the nervous system.

Exclusively as a nervous disease it has been only the last few years we find articles of any moment upon it. Dr. Maudsley says:" "The syphilitic virus usually affects the nervous system more or less severely at one period or another of its action; but in some instances it appears to attack the nervous system specially." This is evident in all constitutional cases, for while the system at first is strong enough to cast it off by an eruption upon the body, yet in the end it develops into a paretic condition of the whole surface. This action will take place sooner if an attempt is made to heal this eruption by external applications. Again we have ulcers in cases of old syphilis, which fail to heal after a great deal of trouble. This condition (which is chronic) is on account of the functional disturbance of the peripheral nerves. The above author ${ }^{2}$ relates a case of acute mania which developed just at or soon after the secondary manifestations of the disease had shown themselves.

I had a case which illustrates this action upon the cere-

1 "Pathology of the Mind," page 200.

" "Pathology of the Mind," page 482. 
bral forces equally as well as Dr. Maudsley's ; and will therefore relate it instead of his.

He was a man, white, about forty-two years of age; born in Pennsylvania, and of respectable parentage; when quite young he was addicted to the use of spirituous liquors, and was also a frequent visitor to houses of ill repute. On one of these visits he acquired syphilis, it being several years before ; and he claimed to have been cured, but I believe the intemperate habit would have rendered inert any medicine he would take.

When I saw him first it was after a protracted spree; and after the clerk had taken his record, and before going to the hospital, ${ }^{1}$ he took an epileptiform convulsion, which I claim was superinduced by alcohol. The syphilitic diathesis was visible in large ulcers upon the lower limbs, and a syphilomatous condition of the skin.

In the several months he was with me he never took another convulsion, but gradually improved in health and appearance; and like most of his kind wandered between the Home and city. Thus I had him several times in the hospital, and the last time I endeavored to heal the ulcers upon his lower limbs; and although they healed nicely, yet it developed acute mania. One day just before supper I was called into the male ward to quell a riot which had broken out among the inmates. There I found them excited at an act this individual had committed. He had apparently for no cause struck and seriously injured an inoffensive boy; and when questioned about it, he gave an incoherent reply. Finding him delirious, I deemed it the safest to confine him in the asylum.

After five months' discipline in this department, he was discharged as cured. And he had not been in the city more than five or six weeks when lie fell in one of the above convulsions and expired. There was no post-mortem, but from the description of his death I supposed it was from cerebral congestion.

The pathology of the disease is obscure, inasmuch as cases of syphilitic paresis generally recover. To study it properly you must examine cases of general progressive paresis where the syphilitic diathesis plays a prominent part. It is, if not an original cause, a fatal adjuvant to the predominant cause, being one of the principal excitants to that

\footnotetext{
${ }^{1}$ City Home Hospital, Pittsburg, $\mathbf{P a}$.
} 
extensive sclerosis of the spinal cord we discover in longcontinued cases of this kind. I might, if permitted, say it appears upon the cord much in the same way a hard chancre appears upon the glans penis.

Syphilitic paresis is not an organic but a functional disturbance, and the virus seems to have its greatest affinity for the cervical cord after it once enters the system, especially the lateral or postero-lateral columns. It then gradually moves downward, affecting the spinal nervous system completely and finally upward upon the cerebral centres.

When the spinal trouble manifests itself we then have the beginning of paresis. Unfortunately, however, for the profession, we seldom gain a case until the cerebral symptoms have occurred. The attack upon the vaso-motor centres brings to notice the spinal trouble.

Dr. H. C. Wood ' relates several cases in which he gained post-mortems which will aid us partially in obtaining a correct idea of the anatomical changes that occur in these cases. I believe later in the disease, that is, when it has passed into a general paralytic condition, the whole cord as well as the cerebral centres are involved in the general degeneration."

Dr. Wood considers there is less known of syphilis of the spine. This is undoubtedly on account of the above assertion, " that the attack upon the vaso-motor centres brings to notice the spinal trouble." I believe cerebral syphilis is a continuation of the spinal disease. Nor could I think as he does that the spinal syphilis is more serious than the cerebral affection, for in the treatment of the case we have the assistance of the patient in spinal disease, while in the cerebral we do not (the patient being unconscious of his action).

\footnotetext{
1 American Journal of Medical Science, vol. 80.

${ }^{2}$ I had several cases of general paresis and all but one had the syphilitic diathesis.
} 
The doctor's case 7 followed much the same course that my cases did, only to a greater extent. In the autopsy he found the following points: The lateral and posterior columns were sclerotic, more especially in the dorsal and cervical cord, and the endoneurium of the posterior roots much proliferated and infiltrated with embryonic pus-cells. The case had passed from a purely functional to an organic disease.

The symptoms of this disease are: slight elevation of the temperature, and severe pain. This pain is constant, its severity being affected only by the rise and fall of the temperature of the room. It is present with stiffness and soreness of all the joints affected, attended with no increased heat or swelling. The sensory filaments seem to retain a partial use of their function, while the motor track, though not entirely obstructed, is, to a greater extent than the sensory. Very little of the body is exempt, the mind at times being affected almost to delirium. This, however, is caused only when the vaso-motor centres are involved. There is a general languor, and the patient is much irritated on being disturbed. The pulse is generally full and strong; heart's impulse strong, especially if there is much cerebral congestion; there is very little or no pyrexia; bowels are generally costive, not so much on their own account as from the pressure of the cerebral forces; urine is generally highcolored and scant. The appetite is affected according to the severity of the pain; the stomach being disturbed through sympathy. The eyes and conjunctiva are affected from the pressure upon the brain. The skin is dry and sallow, and there is generally a tenderness along the spine.

The diagnosis is somewhat difficult, inasmuch as the pain simulates the pain of several complaints-both inflammatory and neuralgic. An early diagnosis is important, 
however, on account of it giving the most favorable results, for out of five cases which I have quoted, I had four recoveries.

Articular rheumatism, an inflammatory disease, is attended with hot, painful, and, later in the disease, swollen joints. The parts are tender, the pain trophic, and there is a general febrile condition.

In synovitis, also an inflammatory disease, the pain, as well as the disease, is trophic, and is attended with swollen, hot, and painful joints. There is no pyrexia except through sympathy later in the disease.

Osteitis, another inflammatory disease, is like synovitis, though it is not confined to the joints, but more often in the shaft.

In myalgia the pain is trophic and constant, but not attended with painful joints. It is located in the terminal filaments of the nerves and is increased by active contrac. tion of the muscles.

In neuralgia the pain is paroxysmal, shooting, lancinating, darting, boring, etc., and is referred along the line of the nerves. It is not constant. If it is from malarial poison, it is periodical. The paroxysm develops spontaneously, or in consequence of some trifling cause not at all commensurate with the severity of the pain produced. A poor condition of a patient's blood, which is almost general, is also a point in diagnosis.

In syphilitic paresis the joints are stiff, not swollen; pain at times trophic but obscure, constant, but the severity of it is regulated by the fall and rise of the temperature of the room. There are also later in the disease vaso-motor disorder, atrophic in character, and congestion of the brain.

The prognosis is favorable at the beginning of the trouble, -that is, before organic trouble commences, and it becomes worse as the patient sinks from a state of irritability into that 
of delirium. It is not, however, hopeless until inflammation sets in, or gummatous tumor develops. Even then the case, under proper treatment, can be prolonged. The patient generally dies of nervous exhaustion.

In the treatment of this disease I believe iodine is the sine qua non. It will, however, depend on the idiosyncrasia of the patient and the amount and kind of medicine that has been before taken, whether iodine in combination with potassium, or in some other form, will be the best way to administer it. If the patient can stand the nauseating effect, there is no better way of taking it than with oleum morrhuæ. Nor would I rely upon iodine alone, although it acts promptly in most cases. The debilitating condition of the patient may call for a tonic and supporting treatment. 